\title{
La prohibición de discriminación por orientación sexual ${ }^{1}$
}

\author{
María Martín Sánchez \\ Profesora doctora de Derecho constitucional \\ Universidad de Castilla-La Mancha
}

Recibido: 21.06 .2010

Aceptado: 30.06 .2010

\begin{abstract}
Resumen: La Constitución Española, en su mandato de igualdad, realiza una prohibición expresa de discriminación en virtud de determinadas causas por recaer sobre ellas una fuerte sospecha de discriminación justificada en fuertes razones históricas de índole social, política, legal e incluso cultural. El devenir social constata que en la actualidad existen nuevas causas equiparables a aquellas, tales como la orientación sexual, rasgo inherente a la persona, tal y como se expresa ya en diversos textos europeos y así como ha afirmado el Tribunal Europeo de Derechos Humanos (TEDH).
\end{abstract}

Palabras clave: Orientación sexual, condición personal, igualdad, discriminación, interpretación constitucional, protección constitucional.

Abstract: The Spanish Constitution, in its article devoted to gender equality, executes the express prohibition of any discrimination based on specific reasons for being these reasons suspicious of a kind of discrimination that can be justified by means of historical facts of social, political, legal or, even, cultural nature. The social development ascertains that nowadays there are a series of reasons comparable to those aforementioned, such as sexual orientation, a characteristic which is inherent in human beings, as it has already been depicted in some European Texts and mentioned by the European Court of Human Rights (ECHR).

Key words: Sexual orientation, human condition, equality, discrimination, constitutional interpretation, constitutional protection.

Sumario: I. Sobre la prohibición de discriminación en la Constitución Española.- II. Protección constitucional de las causas sospechosas de discriminación y apertura a nuevas causas.- III. La orientación sexual como causa prohibida de discriminación.- IV. La protección de la orientación sexual en tratados internacionales sobre derechos fundamentales.V. La interpretación constitucional de la orientación sexual como causa prohibida de discriminación. Efectos jurídicos.-VI. Referencias bibliográficas, normativas y jurisprudenciales.

${ }^{1}$ Véase la monografía de la misma autora: Matrimonio homosexual y Constitución, Tirant lo Blanch, Valencia, 2008. 


\section{Sobre la prohibición de discriminación en la Constitución Española}

El principio de igualdad contenido en el artículo 14 de la Constitución Española (CE) consta de un principio genérico de igualdad y de una prohibición de discriminación traducida en una lista de causas $-\ll \ldots$ nacimiento, raza, sexo, religión, opinión...»-sobre las que pesa una fuerte presunción de discriminación, en el caso de ser utilizadas como causas de distinción entre dos supuestos de hecho. Estas causas vedadas son básicamente de dos tipos: o bien se trata de características inmanentes al ser humano, con las que nace; o bien se trata de características que el individuo adquiere a lo largo de su formación personal, en las que pueden influir multitud de factores como el componente hereditario o las propias decisiones que adopte, en las que además de la igualdad entra en juego el ejercicio de derechos y libertades. Se trata, en este último caso, de derechos y libertades ya reconocidos y protegidos constitucionalmente pero cuya protección se refuerza al estar incluidos en el artículo $14 \mathrm{CE}$, impidiendo de esta forma que se restrinjan hasta límites que, aunque pudieran parecer compatibles con los específicos derechos que los protegen, deben considerarse ilícitos por la irrazonabilidad del criterio utilizado en la distinción realizada ${ }^{2}$. El elenco de causas prohibidas de manera expresa no tiene carácter cerrado sino meramente enumerativo, tal y como quiso precisar el constituyente. Esta intención del constituyente se desprende de su propia redacción, al finalizar el artículo 14 CE de esta forma: «... o cualquier otra condición o circunstancia personal o social»; es, por lo tanto, una lista abierta a la inclusión de nuevas causas, introducidas en virtud de dicha cláusula abierta.

Esta fórmula de cerrar el listado de causas de discriminación prohibidas mediante una cláusula de este tipo no es original de nuestra Constitución. En efecto, la denominada fórmula de las «cláusulas genéricas» es utilizada por numerosos tratados internacionales y constituciones, aunque quizá el ejemplo más claro, que ha servido de modelo a diversos tratados y constituciones posteriores ha sido la Declaración Universal de Derechos del Hombre, la cual ya utilizó este tipo de fórmula en sus trabajos preparatorios. Es fácil justificar la existencia y el empleo de este tipo de cláusulas genéricas; la noción «discriminación» no tiene unos parámetros exactos e inamovibles en virtud de los cuales considerar si por razón de una circunstancia se está o no discriminando; se trata de un concepto evolutivo que cambia con la sociedad, ya que algo que hace cincuenta años podía ser considerado causa de discriminación, puede no serlo ahora por el cambio de ideología y de modo de vida de la sociedad. Además, no es posible que los constituyentes agotasen en una

${ }^{2}$ M. RODRÍGUEZ-PiÑERO y M. ${ }^{a}$ F. FERnÁNDEZ LóPEZ, en Igualdad y discriminación, Colección «Temas Clave de la Constitución Española», Tecnos, Madrid, 1986, págs. 179 y ss. 
lista todas las causas de discriminación en el momento de redacción del texto y, aún menos, las que pudieran venir en tiempos futuros, con lo que este tipo de cláusulas permiten ampliar el listado a posibles causas de discriminación surgidas en un momento posterior a la redacción del texto. Con todo, es preciso limitar la posibilidad de inclusión de causas en las cláusulas genéricas -en nuestro caso en la «cláusula abierta»-, a través del establecimiento de una serie de requisitos o parámetros que habrá de superar la supuesta causa de discriminación para ser considerada como tal -como tendremos ocasión de estudiar más adelante-, ya que no podría admitirse su apertura a cualquier causa, pues entonces perderían su virtuosidad las causas expresamente previstas en el artículo $14 \mathrm{CE}$.

Muchas son las lecturas que se han dado a la llamada «cláusula abierta» o «de apertura» del principio de igualdad. Hay quienes interpretan que no existe separación alguna entre las causas expresas de no discriminación y las basadas en «cualquier otra condición o circunstancia personal o social» -cláusula abierta-; de esta forma, las especificaciones podrían quedar reducidas a meros títulos enunciativos. Por otro lado, puede interpretarse que las causas expresamente protegidas frente a la discriminación en el Texto Constitucional gozan de una naturaleza diferenciada, en el sentido de que son circunstancias que implican un juicio más estricto de igualdad que las distinciones basadas en otros fundamentos cualesquiera. Ahora bien, entendiendo que la lista enumerada expresamente no es un «numerus clausus», sino que con la cláusula abierta se da un margen al Tribunal Constitucional para engrosar el listado de criterios cuya utilización en contra de determinados colectivos ha de ser objeto de un juicio más estricto.

Teniendo en cuenta el reconocimiento del principio de igualdad y de no discriminación previsto por nuestra Constitución, la denominada cláusula abierta ha adquirido en nuestro ordenamiento una gran importancia. Desde nuestra posición, optamos por la protección más estricta. Además, entendemos que si el constituyente quiso incluir la cláusula abierta para permitir la protección de nuevas causas de no discriminación, estas deben ser protegidas del mismo modo que las que se recogieron de forma expresa, siempre y cuando superen determinados parámetros que las conviertan en criterios especialmente sospechosos. En este sentido, para mantener la razón de ser del listado de las causas expresas, debe fijarse una serie de requisitos que actúen a modo de barrera para determinar la inclusión de nuevas causas en la cláusula abierta - esta es la línea seguida por la Jurisprudencia Constitucional $^{3}$-. Siguiendo esta argumentación, se sostendría la posibilidad de que a ciertas causas incluidas como causas prohibidas de discriminación a través de la cláusula abierta, pueda aplicárseles un juicio estricto de igualdad

${ }^{3}$ STC 269/1994, de 3 de octubre, «caso cuota para discapacitados en la Comunidad Canaria». 
-siempre y cuando superen unos determinados parámetros-, al igual que a las causas expresamente previstas por la enumeración del artículo 14 CE. En particular nos referimos a causas que afecten a la dignidad y los derechos de la persona -como la orientación sexual-, en especial si como consecuencia de dicho rasgo dan lugar a un colectivo minoritario, como es el caso del colectivo homosexual.

El Tribunal Constitucional, en su función suprema de garante de la Constitución, aplica el principio de igualdad de distinta forma según se trate de supuestos en los que entre en juego alguna de las causas prohibidas de discriminación expresamente previstas en el artículo 14 o no. Así, podemos advertir la existencia de dos gradaciones en la intensidad de su juicio de igualdad, al existir: un juicio de mínimos, en el juicio ordinario de igualdad, aplicado sobre toda discriminación normativa; y un juicio estricto, o juicio agravado de igualdad, aplicado sobre discriminaciones derivadas de las cláusulas específicas de no discriminación y de la afectación de derechos fundamentales. Ambos juicios tienen la misma estructura, y se dividen en dos fases: juicio de la razonabilidad de la clasificación legislativa y juicio de la proporcionalidad de la diferencia de trato. El esquema seguido en ambos test de igualdad es el mismo, con la salvedad de que el juicio estricto se regirá por técnicas propias, siguiendo determinados parámetros que endurecen la perspectiva del juicio.

Analizaremos a continuación el juicio estricto de igualdad que, como ya hemos explicado, se trata de un juicio mucho más exhaustivo de los parámetros de igualdad, para estudiar luego su aplicación a nuestro objeto de estudio. Es cierto que en un Estado como el nuestro, definido en nuestra Carta Magna como un Estado Social y Democrático de Derecho, prima como elemento esencial el respeto a la voluntad soberana del legislador y a su escala de valores. En toda democracia son las mayorías quienes imponen sus opciones políticas al colectivo social. Sin embargo, en las democracias actuales se hace necesario establecer determinados límites a la voluntad de la mayoría, límites que se verán reflejados en la labor del legislador y, sobre todo, en la propia Constitución, al reconocer una serie de derechos a la persona -«para todos»- en cuyo contenido esencial ninguna ley podrá limitar; en consecuencia, la Constitución es protectora de las minorías -políticamente más débiles- frente a la voluntad política de las mayorías. Estos límites tienen varios objetivos, entre los que destacan el respeto al individuo, a las minorías y, en última instancia, el aseguramiento de la efectividad del principio de igualdad. La cuestión es que para alcanzar dicha efectividad frente a las mayorías no es suficiente con el juicio de mínimos anteriormente expuesto, razón por la que el Tribunal Constitucional utiliza el juicio estricto de igualdad para aquellos supuestos en los que, o bien se afecta a alguna de las causas expresas de no discriminación contenidas en el segundo inciso del precepto $-\ll \ldots$ sin que pueda prevalecer discriminación alguna por razón de nacimiento, raza, sexo, religión, opinión...»-, o bien se limitan derechos fundamenta- 
les. Por este motivo, consideramos que la única fórmula para que las minorías sometidas a tratos desiguales por alguna causa encuadrable en la cláusula abierta, que supere una serie de parámetros, alcancen la plena igualdad, es aplicar a dicha causa un juicio más estricto.

Tal y como apuntamos, la estructura del juicio estricto es exactamente la misma que la del juicio de mínimos, ya que, en realidad, se trata del mismo test de igualdad, con la diferencia de que el juicio estricto se rige por técnicas propias que lo endurecen. Los puntos en que el juicio de igualdad se hace más riguroso en el juicio estricto son, fundamentalmente, la exigencia de vinculación de las diferentes situaciones jurídicas a la razón de ser de la norma; y la determinación de la constitucionalidad de la finalidad legislativa.

1) En cuanto al primer requisito, se refiere a determinar si los supuestos de hecho son similares y, por ello, equiparables, y como consecuencia dilucidar si la diferencia de trato aplicada es o no inconstitucional. La búsqueda de la diferencia entre supuestos de hecho no ha de realizarse mediante una comparación entre las diferencias fácticas entre ambos supuestos, sino a través del fundamento de la norma, es decir, mediante la comprobación de si los distintos supuestos aparecen jurídicamente diferentes o no respecto a dicho fundamento.

2) El segundo requisito en que se manifiesta el juicio estricto es la determinación de la constitucionalidad de la finalidad legislativa. Este extremo tiene especial relevancia ya que, mientras el juicio estricto se centra en la legitimidad de la finalidad de la diferencia de trato, en el juicio de mínimos se realiza una simple comprobación de que la finalidad de la norma no sea manifiestamente contraria a la Constitución. En este punto desaparece la presunción de legitimidad del legislador de que goza en el juicio de mínimos, en el sentido de que debe argumentarse la constitucionalidad de la medida diferenciadora adoptada por el legislador, ya que aquí el elemento más importante del juicio estricto es el análisis de la finalidad de la diferencia de trato. El propio Tribunal Constitucional exige de forma implícita otorgar esta especial relevancia a la finalidad de la norma a través de la aplicación del juicio estricto de proporcionalidad, endureciendo los términos. Dependiendo de si la norma encarna un valor constitucional, o no tendrá mayor o menor trascendencia su finalidad. Esto supone la necesidad de analizar qué valores encierra cada norma constitucional además de interpretar las leyes sometidas al control de constitucionalidad en atención a dichos valores. Igualmente, si de valores se trata, cuando se produzca una colisión entre ellos, habrá que acudir a la ponderación para determinar cuál prevalecerá atendiendo a las circunstancias del caso en concreto. En suma, se considerará que las leyes que tengan como finalidad alguno de estos valores constitucionales tendrán una finalidad constitucional especialmente importante. Tan solo hace falta una cierta relación objetiva entre la norma y ese valor constitucional para que el Tribunal objetive mediante dicho valor la finalidad de la ley. 
El gran problema es la búsqueda de la finalidad auténtica de la norma, ya que en muchas ocasiones esta está encubierta, apareciendo lo que se denomina discriminación encubierta o discriminación indirecta, en las que a veces es difícil descubrir o justificar la auténtica finalidad encubierta.

\section{Protección constitucional de las causas sospechosas de discriminación y apertura a nuevas causas}

Una vez admitida la posibilidad de aplicar el juicio estricto a determinadas clasificaciones legislativas que perjudican a ciertos grupos o colectivos, tras la catalogación de la causa origen de su discriminación como perteneciente a la cláusula abierta, se presenta un grave problema: fijar los parámetros en virtud de los que el Tribunal Constitucional habrá de determinar a qué grupos, en virtud de cuya causa incluida en la cláusula abierta, puede aplicárseles un test de igualdad más estricto y a cuáles no. Así, mientras otras jurisdicciones constitucionales han resuelto el problema fijando los rasgos diferenciadores del grupo necesarios para aplicarle dicho test, no ha ocurrido lo mismo en la nuestra, en la que la cuestión sigue sin resolverse.

Ciertamente, no es fácil determinar la pertenencia de una causa -caracterizadora de un colectivo o grupo minoritario- a la cláusula abierta del artículo 14 CE. El Tribunal Supremo Americano es el que más ha esclarecido la cuestión, puesto que recordemos que en la Constitución de EE. UU. tan solo se recoge una cláusula genérica de igualdad y es el Tribunal Supremo el que ha tenido que delimitar jurisprudencialmente las causas especialmente protegidas. Así, el Tribunal Supremo fijó una serie de parámetros que debe superar el colectivo o grupo minoritario para poder acogerse al juicio estricto. Sin embargo, no podríamos trasladar directamente la doctrina del Tribunal Supremo Americano a nuestro ordenamiento jurídico debido a la disparidad existente entre ambas realidades jurídicas.

El Tribunal Constitucional español no se ha pronunciado al respecto dando los requisitos necesarios para proteger a un colectivo bajo la cláusula abierta, ni ha establecido los parámetros en función de los cuales ampliar la protección reforzada garantizada a las causas expresamente prohibidas en el artículo $14 \mathrm{CE}$, a través del juicio estricto de igualdad. Con todo, solo así adquiriría pleno sentido el carácter abierto y no taxativo de la lista de causas de no discriminación expresamente previstas en el artículo $14 \mathrm{CE}$.

Por ello, recurriremos a una serie de parámetros sacados de Derecho Comparado -en la medida en que se ajusten al nuestro- y de la propia jurisprudencia del Tribunal Constitucional español. De este modo, planteamos como requisitos los siguientes: compartir un rasgo en común que los identifique como grupo, existencia de una historia de discriminación, disminución de la posibilidad de defensa de los intereses del colectivo en el proceso polí- 
tico que condujo a la creación de la norma en cuestión, y existencia de prejuicios sociales negativos contra dichos colectivos susceptibles de ser reforzados con la distinción normativa ${ }^{4}$.

- En cuanto al primero de los rasgos compartir un rasgo común que los identifique como grupo, supone que el rasgo los identifique como grupo y constituya la razón por la que han padecido una historia de discriminación y se les ha marginado tanto política como socialmente.

- El segundo de los rasgos es la historia de discriminación sufrida por el grupo, tanto social como jurídicamente.

- El tercer rasgo consiste en la disminución de la posibilidad de defensa de los intereses del colectivo minoritario en el proceso político mediante el cual se creó la norma. Este es un rasgo tomado de la jurisprudencia del Tribunal Supremo Americano, no utilizado por la española ${ }^{5}$. La tesis en que radica este parámetro es la necesidad de aplicar el juicio estricto de igualdad sobre clasificaciones normativas que perjudican a determinados colectivos que tienen razones históricas para desconfiar del legislador.

Cuando un colectivo no está incluido entre las causas expresamente prohibidas del artículo $14 \mathrm{CE}$, sino que se puede incluir en la cláusula abierta, una razón básica para evitar el juicio de mínimos es demostrar que algo no ha funcionado en el proceso legislativo, que ha habido un rechazo hacia ellos por parte de quienes elaboraron la norma, o bien que han estado subrepresentados en dicho proceso, causas perjudiciales para sus intereses y que llevarían a sospechar, pues la diferencia de trato a la que han quedado sometidos y por la que resultarían perjudicados es contraria al principio de igualdad del grupo minoritario. Este análisis parece muy eficaz, ya que consideramos que este es un parámetro que no puede desconocerse, no tanto por la subrepresentación política de los grupos desfavorecidos en la toma de decisiones de las normas legislativas, sino en cuanto al rechazo social hacia ellos por parte de quienes las toman, lo cual hace que en muchos casos la mayoría domine a minorías que la mayoría de las veces no son oídas y alguna vez parecen no existir.

- Finalmente, el cuarto y último de los rasgos necesarios para la inclusión en la cláusula abierta es la existencia de prejuicios sociales contra dicho

${ }^{4} \mathrm{El}$ autor de estos rasgos ha sido GiMÉnEz GLUCK, tomando como referencia la doctrina del Tribunal Supremo Americano y la práctica de la jurisprudencia de nuestro Tribunal Constitucional. Véase su tesis doctoral: La cláusula de igualdad en la Jurisprudencia del Tribunal Constitucional; así como Una manifestación polémica del principio de igualdad: acciones positivas moderadas y medidas de discriminación inversa, Tirant Monografías, Madrid, 1998, págs. 33 y ss.

${ }^{5}$ Rasgo utilizado por autores como GIMÉNEZ GLUCK, como rasgo o parámetro innovador. 
grupo, susceptibles de ser reforzados con la diferenciación normativa. Se presume que existen prejuicios sociales cuando hay una situación de inferioridad social o legal de ciertos colectivos. Ahora bien, cuando existe un colectivo con un rasgo común respecto al que existen prejuicios, las normas que hagan clasificaciones legislativas basadas en el rasgo que caracteriza a dicho colectivo pueden perjudicar a los miembros del colectivo y son sospechosas de inconstitucionalidad. Por este motivo habría que aplicarles el juicio estricto de igualdad.

\section{La orientación sexual como causa prohibida de discriminación}

En relación con la orientación sexual, existen diversos ámbitos en los que se ha obviado el carácter de esta como «condición o circunstancia personal o social» del individuo, permitiéndose así el establecimiento de medidas diferenciadoras en virtud de ella.

En concreto, en el ámbito de las relaciones personales y familiares, encontramos que, hasta la fecha, solo se ha tenido en cuenta a las uniones de hecho, presuponiéndolas heterosexuales ${ }^{6}$-puesto que el Tribunal Constitucional no se ha pronunciado sobre su equiparación a las homosexuales-, catalogándolas a la hora de emitir un juicio de igualdad sobre su situación en comparación con los matrimonios como una excepción al juicio de mínimos por irracionalidad de la norma, pero sin poder incluirlas en el juicio estricto de igualdad por no cumplir con los requisitos exigidos para ello. Sin embargo, aún queda por dilucidar cuál es el juicio de igualdad más oportuno para juzgar la situación de las uniones de homosexuales -como colectivo minoritario y desfavorecido, tal y como se ha argumentado en la parte histórica-. Parece claro que no cabe para este grupo de personas un juicio tan superficial como es el de mínimos, ya no solo por la directa convalidación de las normas que presumimos discriminatorias que supondría la aplicación de dicho juicio de mínimos, dejándolos en una situación de clara desventaja respecto al resto de la sociedad -mayoritariamente heterosexual-, sino sobre todo por un elemento importantísimo que entra en juego al hablar de unión homosexual, como es, la «orientación sexual».

No es discutible que la orientación sexual no se encuentra entre la lista de causas expresas de no discriminación del artículo $14 \mathrm{CE}$; sin embargo, tampoco lo es que esta no es una lista cerrada sino abierta por el constituyente a otras posibilidades, gracias a la cláusula abierta: «cualquier otra condición o circunstancia personal o social». En nuestro país han sido varios los colectivos que han luchado por el reconocimiento de su causa de discrimina-

${ }^{6}$ En las SSTC, el Tribunal Constitucional se ha referido siempre a parejas heterosexuales sin equipararlas a las homosexuales. 
ción ${ }^{7}$ como causa asimilable a las causas expresas del artículo $14 \mathrm{CE}$-criterios especialmente sospechosos-, a pesar de que finalmente el Tribunal Constitucional solo ha reconocido la de discapacidad. Una de estas causas ha sido la «orientación sexual».

En principio, no haría falta ahondar mucho en su estudio para admitir que, si existe una condición o circunstancia que pueda afectar directamente a alguien personal o socialmente, es su orientación sexual; pueden existir otras, pero quizá esa es la condición personal o social que marca de modo más radical a cada persona y, precisamente por ello, debe excluirse de todo tipo de discriminación con base en dicha causa. Así pues, trataremos de argumentar que esta causa supera todos los parámetros exigibles para su inclusión en la cláusula abierta y así poder ser enjuiciada desde el prisma del test estricto de igualdad.

El motivo de esta falta de reconocimiento expreso de la orientación sexual en el artículo 14 del Texto Constitucional está muy relacionado con el hecho de que la concienciación y preocupación de la discriminación sufrida por los homosexuales es algo reciente, surgido en las sociedades más actuales, que no había previsto el constituyente en la época en que se redactó la Constitución. Es necesario por tanto realizar una labor de interpretación constitucional, ya que solo a través de ella pueden adaptarse las normas constitucionales a la época de su aplicación, ajustándose a la evolución y a las nuevas exigencias apremiantes desde la sociedad. Esta labor de interpretación constitucional conforme a la evolución social es posible gracias al carácter abierto y flexible del texto, que apuesta por hacer de la Constitución una interpretación acorde a la nueva realidad social ${ }^{8}$. En la misma línea, la doctrina española ${ }^{9}$ defiende el carácter abierto de la Constitución, sosteniendo no solo la posibilidad de interpretarla flexiblemente conforme a las necesidades surgidas con los cambios sociales, sino incluso la posibilidad de crear nuevos derechos constitucionales, también surgidos por necesidades propias de la nueva realidad ${ }^{10}$.

\footnotetext{
${ }^{7}$ Las causas pretendidas como causas prohibidas de discriminación incluidas en la cláusula abierta del artículo $14 \mathrm{CE}$, con la finalidad de proteger a ciertos colectivos, han sido las siguientes: edad, parentesco, clase social, lengua, orientación sexual y discapacidad. Sin embargo, tan solo la discapacidad ha sido reconocida por el Tribunal Constitucional como causa incluida en la cláusula abierta, totalmente asimilable a efectos de no discriminación a las causas expresas en el artículo $14 \mathrm{CE}$.

${ }^{8}$ Véase K. Hesse, Escritos de Derecho Constitucional, selección, traducción e introducción de Pedro Cruz Villalón, II edición, Centro de Estudios Constitucionales, Madrid, 1992.

${ }^{9}$ Véase F. J. DíAz Revorio, en La Constitución como orden abierto, Mc Graw Hill, Madrid, 1997; en especial págs. 181 y ss.

${ }^{10}$ Tesis defendida por F. J. DíAz REvorio, Valores superiores e interpretación constitucional, Centro de Estudio Políticos y Constitucionales, Madrid, 1997, págs. 451-455 y 529 y ss.
} 
Podría pensarse que es más sencillo incluir la orientación sexual entre las causas expresas a través de una reconducción de la prohibición de discriminación por sexo o «discriminación por género» ${ }^{11}$. Sin embargo, la causa de discriminación no es la misma en la orientación sexual que en el sexo; no es lo mismo ser discriminado por ser de sexo diferente que por tener una orientación sexual distinta ${ }^{12}$. Por ello, nos reiteramos en que la solución es entender la «orientación sexual» como causa asimilada a las expresamente prohibidas de discriminación en el artículo $14 \mathrm{CE}$, una vez reconocida su inclusión en la cláusula abierta y habiendo superado determinados parámetros.

En España la «orientación sexual» no ha sido objeto de gran atención por la doctrina jurídica. Tal vez es su falta de interés y estudio la que propicia que quizá no exista hasta el momento suficiente base doctrinal ni jurisprudencial para aplicarle el juicio estricto de igualdad, lo cual no significa que carezca de fundamentos para ello. Al contrario, creemos que se ajusta plenamente a la característica de «condición personal o social». Además, apostamos por su inclusión en la cláusula abierta, teniendo en cuenta la interpretación conjunta con ciertos textos internacionales sobre derechos fundamentales, especialmente en el ámbito comunitario, donde ya se empieza a prohibir específicamente la orientación sexual como causa expresamente tasada ${ }^{13}$. Para ello, nos corresponde ahora justificar que, efectivamente, la orientación sexual se ajusta a los parámetros ${ }^{14}$ anteriormente enunciados como criterios utilizados para su asimilación a las causas expresamente prohibidas y así poder aplicarle un test estricto de igualdad ${ }^{15}$ :

${ }^{11}$ En este sentido, véase también F. REY MARTíNEZ, en El derecho fundamental a no ser discriminado por razón de sexo, Mc Graw Hill, Madrid, 1995, págs. 57 y ss. Este autor, siguiendo la misma línea, es defensor de la igualdad de trato entre ambos sexos, apostando por la paridad y por las acciones positivas para alcanzar tal igualdad. Sin embargo limita el uso de las acciones positivas a las causas expresamente enumeradas en el artículo 14 de la Constitución Española, por lo que no incluye de ningún modo la «tendencia sexual» en la categoría «sexo», sino que esta quedaría fuera de tal elenco -no descartando su inclusión en la «cláusula abierta»-.

${ }^{12} \mathrm{Al}$ respecto véase M. RODRÍGUEZ-PiÑERO y M. ${ }^{\mathrm{a}}$ F. FERnÁNDEZ LóPEZ, Igualdad y..., ob. cit.

${ }^{13}$ El epígrafe siguiente está dedicado a esta cuestión: «La interpretación de la orientación sexual a la luz de los Tratados Internacionales sobre derechos fundamentales, en conformidad con el artículo 10.2 CE».

${ }^{14}$ Recordemos que se tratan de parámetros sacados del Derecho Comparado -acordes con nuestro ordenamiento jurídico-y de la jurisprudencia del Tribunal Constitucional. Estos eran los siguientes: compartir un rasgo común que los identifique como grupo, por el cual son discriminados; historia de discriminación común; disminución de la posibilidad de defensa de los intereses del colectivo en el proceso político que condujo a la creación de la norma; prejuicios sociales contra el colectivo que les haga susceptibles de ser reforzados con la diferenciación normativa.

${ }^{15}$ Parámetros propuestos por Giménez Gluck, aportados en su tesis doctoral: La cláusula de igualdad en la..., ob. cit. en la que analiza la «homosexualidad» como causa con cabida en la «cláusula abierta» del artículo $14 \mathrm{CE}$, por darse en ella los parámetros requeridos. 


\section{Compartir un rasgo común que los identifique como grupo}

En el caso de la «orientación sexual», esta tiene una base hormonal y genética, común en todo el colectivo homosexual que es discriminado por esta causa. La homosexualidad no se ve ni se toca, es innato a cada uno, del mismo modo que la heterosexualidad es simplemente una condición sexual diferente, pero no existe un rasgo externo que la denote. Cada cual lo lleva en sus genes, en la cantidad de hormonas, y ese es el rasgo común identificador del colectivo homosexual.

Muchas veces, desde el principio de los tiempos, se ha hablado de «antinatural», «contra naturaleza», al referirse a la homosexualidad, pero ¿qué significan realmente los términos «naturaleza» 0 «antinatural»? Una primera idea de lo «antinatural», radica en la falta de reproducción, según la cual se ha intentado argumentar que el comportamiento sexual en sí mismo no reproductivo es «antinatural». No parece justificar, sin embargo, la intolerancia hacia este tipo de relaciones en ninguna de las épocas en que así ha ocurrido. Basta para ello recordar que en todas las sociedades, desde las más antiguas hasta las más modernas, se han permitido como naturales comportamientos sexuales -según la época- que tampoco son en sí mismos reproductivos, sino que «tienen consecuencias reproductivas idénticas a las de la actividad homosexual» ${ }^{16}$, es decir, nulas.

Otro argumento histórico para apoyar la «antinaturalidad» del comportamiento homosexual ha sido la idea de que la homosexualidad solo se da en la especie humana pero no en ningún otro animal. Esta teoría intenta justificar que es un comportamiento antinatural porque, al no darse naturalmente entre animales, se trata de un comportamiento antinatural. No hay mucho que explicar para demostrar el error de esta teoría. Está comprobado que existen comportamientos homosexuales prácticamente en todas las especies animales y claro es que nadie dirá que estos comportamientos son antinaturales, sino parte de la naturaleza.

Por último, existe una idea para explicar la antinaturalidad que se aparta completamente de la dicotomía «natural-antinatural», para centrarse en la llamada naturaleza ideal. Esta teoría parte de una naturaleza perfecta, frente a lo predeterminado lo diferente se califica como vicioso, perverso o malo y, por tanto, «antinatural», ya que la naturaleza no puede en ningún caso generar el mal. Así las cosas, una conducta como la homosexualidad, calificable como viciosa o perversa y repudiada por la sociedad, no puede haberla creado o generado la naturaleza, porque es una conducta mala. Por ello se

${ }^{16}$ J. Boswell, Cristianismo, tolerancia social y homosexualidad, Biblioteca Atajos, Barcelona, 1998, pág. 34, refiriéndose en este caso a prácticas sexuales como el celibato o la masturbación, a las que podríamos añadir otras como las prácticas heterosexuales estériles o la impotencia. 
considera antinatural, independientemente de que la practiquen los animales o los seres humanos. Sin embargo, esta idea preconcebida de una naturaleza perfecta e ideal no es sostenible, como tampoco lo es una catalogación de la homosexualidad como perversa y mala. Estas nociones no tienen fundamento ni científico ni moral; más bien son el resultado de la fusión entre prejuicios históricos e ideas erróneas sobre la naturaleza.

\section{Historia de discriminación}

La historia del prejuicio contra la homosexualidad no es, pues, sino la historia de la intolerancia social. En efecto, son muy pocas las épocas en las que se les ha respetado, en comparación con la cantidad de siglos y en la multitud de sociedades en las que se les ha reprimido, fruto de la intolerancia. Como hemos observado, examinando cada una de las épocas, sociedades y culturas que nos han precedido, desde los pueblos prehistóricos hasta la sociedad democrática española, el tratamiento que se ha dado siempre a la homosexualidad no ha dependido tanto de leyes u otras cuestiones, sino de tolerancia y, en función de esta, ha girado todo lo demás ${ }^{17}$.

Si observamos detenidamente la historia del prejuicio contra los homosexuales, como minoría, es fácil descubrir que nunca son un grupo aislado en su tratamiento hostil o tolerado, en cualquier sociedad en la que se realice el estudio. Junto a los homosexuales, aparecen otros grupos minoritarios -minorías religiosas- que, a lo largo de la historia, han sufrido el mismo tratamiento que ellos, fruto de la intolerancia/tolerancia social. De este modo, la mayoría de las sociedades que admitían la diversidad religiosa, admitían también la variedad de orientación sexual. En la misma línea, las sociedades que oprimieron a las minorías religiosas oprimían a los homosexuales -recordemos que los mismos grupos que oprimían y exterminaban a los judíos en campos de concentración, trataron de hacer lo mismo con los homosexuales-.

En España, y como ya hemos tenido oportunidad de analizar en el capítulo I, la homosexualidad tiene una historia ampliamente justificada de discriminación social y legal que ha continuado manteniéndose hasta la promulgación de nuestra Constitución de 1978. Incluso tras la entrada en vigor de nuestra Carta Magna aún parecen mantenerse vestigios a través de restricciones de derechos, sobre todo en ciertos campos que parecen estarles vetados a quienes tienen una opción sexual diferente a la mayoría, precisamente por esta causa.

Con la llegada de la democracia, llegó la tolerancia hacia los homosexuales -como ya explicamos en páginas anteriores-y empezaron a ser reconocidos públicamente, constituyéndose como grupo, minoritario respecto a

${ }^{17}$ La catalogación de la homosexualidad: pecado, delito, enfermedad... 
la sociedad mayoritariamente heterosexual; es decir, se conformaron como «minoría», manteniéndose respecto a ellos discriminaciones normativas al negárseles derechos solo reconocidos para heterosexuales en el ámbito de las relaciones de pareja. Estas restricciones de derechos -restricción del derecho al matrimonio, e incluso del reconocimiento de los derechos concedidos a las uniones de hecho heterosexuales- siguieron vigentes hasta fechas recientes en que mediante la aprobación de leyes autonómicas se empezaron a reconocer jurídicamente este tipo de parejas, concediéndoseles ciertos derechos de pareja y, finalmente, mediante la ley 13/2005, de 1 de julio, para la modificación del Código Civil en materia de derecho al matrimonio, con la que el Gobierno de la nación terminó definitivamente con todo tipo de restricciones para parejas por razón de su orientación sexual

\section{Disminución de la posibilidad de defensa de los intereses del colectivo} minoritario en el proceso político mediante el cuál se creó la norma

En el caso que nos ocupa -orientación sexual-, esta es sin duda una de las causas más susceptibles de haber provocado en las mayorías políticas actitudes de rechazo social hacia ellas. Además, es evidente la influencia y presión ejercidas por la sociedad -mediatizada también por leyes y políticas represivas hasta muy recientemente- para dañar la imagen pública de los homosexuales, obstaculizando así su inclusión en el plano político. Esto es debido a su ya analizada «posición no dominante», que caracteriza al grupo minoritario como minoría; posición que se hace especialmente relevante en el plano político a la hora de tomar decisiones. Consecuentemente, este colectivo no cuenta con una defensa política objetiva de sus intereses.

Debido a la intolerancia social que han sufrido, los homosexuales casi siempre han permanecido ocultos, en el anonimato. Tan solo en las culturas más tolerantes se han dado a conocer, formando una especie de subculturas, algo así como grupos para hacerse visibles. La intolerancia social, causa de este ocultismo, ha obstaculizado la actuación de la minoría homosexual en el plano público, al no confesar públicamente su condición homosexual. Por esta causa, se les ha imposibilitado ejercer una presencia política equilibrada.

4. Existencia de prejuicios sociales contra dicho grupo, susceptibles de ser reforzados con la diferenciación normativa

La orientación sexual no solo ha sufrido prejuicios sociales en el pasado, sino que sigue siendo objeto de ellos en la actualidad, tras treinta años de democracia, aunque con distinta intensidad. Como ya se explicó en el capítulo I, tras la llegada de la democracia y con la Constitución Española en vigor, el Tribunal Supremo dictó una serie de sentencias en las que calificó a la homosexualidad como «viciosa o perversa», «nociva y peligrosa para la 
sociedad», «aberración», «temible y digna de castigo», etc. Incluso en el año 1991 , la seguía calificando como un «acto contra natura» ${ }^{18}$. En el plano de la Administración, RENFE equiparó a los homosexuales con los drogadictos y prostitutas, catalogándolos como «grupo de riesgo». Actualmente, la sociedad cada vez está más concienciada con la causa, reconoce sus derechos y empieza a ser más tolerante, aunque persisten aún ciertos prejuicios hacia dicho colectivo.

En conclusión, la «orientación sexual» cumple con los cuatro parámetros caracterizadores de las causas especialmente sospechosas de discriminación, esto es, resulta susceptible de la aplicación de un juicio estricto de igualdad, por lo que debería aplicársele tal juicio. El problema es que ni el Tribunal Constitucional ha asumido como propios dichos parámetros, ni tampoco ha admitido expresamente la inclusión de la orientación sexual en la cláusula abierta, evitando así su asimilación a las causas expresas y la aplicación del test estricto de igualdad ${ }^{19}$.

\section{La protección de la orientación sexual en tratados internacionales sobre derechos fundamentales}

No podemos olvidar el mandato constitucional de interpretar las normas relativas a derechos fundamentales y libertades de acuerdo con los tratados internacionales sobre la materia firmados por España ${ }^{20}$. En consecuencia, habrá de interpretarse el artículo $14 \mathrm{CE}$, tratándose de una de las normas constitucionales más directamente relacionadas con la interpretación y aplicación de los derechos fundamentales y libertades, de conformidad con dicha previsión constitucional.

${ }^{18}$ STS, de 15 de noviembre de 1991.

${ }^{19}$ La primera ocasión en que el Tribunal Constitucional se enfrentó a una discriminación directa contra el colectivo homosexual convalidó la norma como constitucional. Esto fue mediante Auto 446/1984, de 11 de julio, de «declaración de constitucionalidad del artículo 352 del Código de Justicia Militar» (ya derogado). Dicho artículo 352 C.J.Militar imponía una pena «al militar que cometa actos deshonestos con individuos del mismo sexo». En este caso en Tribunal Constitucional aplicó el juicio de mínimos, según el cual el Tribunal estimó que no existía una posible similitud entre las relaciones homosexuales y el término de comparación propuesto -las relaciones heterosexuales- por lo que niega que se pueda entrar a juzgar el asunto.

Esta postura fue ratificada después por el Tribunal Constitucional en su STC 33/1985, de 7 de marzo, ya que para el Tribunal la homosexualidad -orientación sexual-, no suponía un rasgo «sospechoso» de discriminación.

${ }^{20}$ Artículo 10.2 CE: «Las normas relativas a los derechos fundamentales y a las libertades que la Constitución reconoce se interpretarán de conformidad con la Declaración Universal de Derechos Humanos y los tratados y acuerdos internacionales sobre las mismas materias ratificados por España». 
Así las cosas, si bien los parámetros a los que nos hemos referido anteriormente, procedentes de la jurisprudencia del Tribunal Supremo americano no han sido por ahora asumidos ni aplicados por el Tribunal Constitucional, encontramos aquí otra vía interpretativa.

Teniendo en cuenta el carácter abierto que da a la lista la cláusula abierta, así como el mandato dado por el artículo 10.2 CE, encontraríamos una nueva vía para argumentar la equiparación de la «orientación sexual» al resto de causas expresamente prohibidas de discriminación. Desde esta argumentación, se defiende la adecuación de nuestra Carta Magna a ciertos tratados internacionales sobre la materia-derechos fundamentales- que, en su tratamiento de la igualdad, hacen prohibición expresa de la discriminación basada en la orientación sexual de la misma manera que el resto de causas tradicionalmente prohibidas. Así ocurre con la Constitución Europea -ratificada por España, aunque sin efectos por su falta de entrada en vigor-. Como es sabido, el proyecto de Constitución Europea contiene una parte dedicada a derechos fundamentales, que no es sino una trascripción de la Carta de los Derechos Fundamentales de la Unión Europea de 2000, entre los que se encuentra el artículo II-81, dedicado a la prohibición de discriminación (reproducción del artículo 21 de la Carta).

La diferencia entre ambos textos - Carta de los Derechos Fundamentales de la Unión Europea y Constitución Europea- es importante, ya que mientras el primero es una mera declaración de derechos, el segundo, por tratarse de un tratado internacional, tendría, en su caso, plenos efectos jurídicos, vinculantes para las partes firmantes. Por este motivo, el precepto que recoge la igualdad y el derecho a no ser discriminados, aunque mantiene la misma redacción en los dos textos, adquiere eficacia jurídica.

Se trata del artículo II-81 (Tratado para la Constitución Europea) -no discriminación-: 1. «se prohíbe toda discriminación, y en particular la ejercida por razón de sexo, raza, color, orígenes étnicos o sociales, características genéticas, lengua, religión o convicciones, opiniones políticas o de cualquier otro tipo, pertenencia a una minoría nacional, patrimonio, nacimiento, discapacidad, edad u orientación sexual»; 2. «se prohíbe toda discriminación por razón de nacionalidad en el ámbito de aplicación del Tratado Constitutivo de la Comunidad Europea y del Tratado de la Unión Europea y sin perjuicio de las disposiciones particulares de dichos Tratados».

Así las cosas, en la Constitución Europea la «orientación sexual» constituirá una de las causas expresamente prohibidas de discriminación, por lo que cualquier medida fundada en dicha causa deberá superar un juicio estricto que justifique el trato diferenciado, argumentando así su constitucionalidad.

El nuestro será, en su momento, uno de los Estados firmantes de la Constitución Europea -de hecho ya la ratificó-, lo cual plantea ciertos interrogantes respecto a la cuestión que abordamos. Una vez ratificado el texto europeo se hará necesaria una interpretación conforme con el Texto ratificado. 
Este prohíbe expresamente la discriminación por «orientación sexual», mientras que la Constitución Española no lo prevé en su listado de causas prohibidas de discriminación; en consecuencia, habría que considerarla incluida en la cláusula abierta prevista por el constituyente, con lo que debería recibir el mismo tratamiento que las causas expresamente prohibidas, esto es, juicio estricto.

La requerida equiparación de la orientación sexual al resto de causas expresas se viene a convertir finalmente en exigencia jurídica, consecuencia del deber de acomodarnos al derecho comunitario.

Esta argumentación no obstante, se construye esencialmente sobre la redacción de un Texto comunitario aún no aprobado. Sin embargo, existen otros argumentos en el Derecho Comunitario para sustentarlo, en tanto dicho texto vea la luz. Dichos argumentos evidencian el cambio jurídico que el panorama internacional está experimentando en la materia concerniente a nuestro objeto de estudio, y que compelen en cierta forma a nuestro ordenamiento jurídico interno a acomodarse a la nueva situación.

Así, en algunos textos ${ }^{21}$, se otorgó a la orientación sexual la categoría de causa sospechosa de discriminación, expresamente prevista como tal, con la finalidad de promover la igualdad en su sentido más amplio -Tratado de Ámsterdam y ciertas Resoluciones del Parlamento Europeo-; otros en cambio no la prevén expresamente, aunque sí explicitan la igualdad de trato en general $^{22}$ y su claro propósito de lucha contra la discriminación.

Por todo ello, insistimos en la importancia de las exigencias internacionales sobre nuestro orden constitucional interno en materia de derechos humanos, tal y como afirma L. M. DíEz PiCAZO: «los límites internacionales más intensos y frecuentes al poder constituyente vienen dados, (...), por los tratados internacionales sobre derechos humanos $(\ldots) »^{23}$. Por otra parte, las

${ }^{21}$ Artículo 13 del Tratado de Ámsterdam: «el Consejo, por unanimidad, a propuesta de la Comisión y previa consulta al Parlamento Europeo, podrá adoptar acciones adecuadas para luchar contra la discriminación por motivos de sexo, de origen racial o étnico, religión o convicciones, discapacidad, edad u orientación sexual». También es destacable por su contenido la Resolución del Parlamento Europeo de 1994, elaborada para la Igualdad de homosexuales y lesbianas..., con la deficiencia de que no tiene fuerza vinculante; en esencia «reitera su convicción de que todos los ciudadanos y ciudadanas tienen derecho a un trato idéntico, con independencia de su orientación sexual». Sobre esta Resolución, véase capítulo I.

${ }^{22}$ Directiva 2000/78/CE, del Consejo de 27 de noviembre de 2000, relativa al establecimiento de un marco general para la igualdad de trato en el empleo y la ocupación. También podemos destacar la Decisión del Consejo de 27 de noviembre de 2000, por la que se establece un programa de acción comunitario para luchar contra la discriminación (20002006).

${ }^{23}$ L. M. ${ }^{a}$ DíEz PiCAzo, «Límites internacionales al poder constituyente», en Revista Española de Derecho Constitucional, núm. 76, 2006, págs. 9-31, en pág. 17. 
normas de los Tratados internacionales sobre derechos humanos, tales como la Declaración Universal de Derechos o el Convenio Europeo de Derechos Humanos, no deben ser tenidas solo en cuanto a su literalidad, sino que además, y por exigencia jurídica, deberá atenderse también al cuerpo jurisprudencial dictado en relación con los derechos en ellos recogidos. En el caso del Convenio Europeo de Derechos Humanos, será el Tribunal Europeo de Derechos Humanos el encargado de interpretar el significado y el contenido de los derechos proclamados por el Convenio ${ }^{24}$.

Por todo ello, nuestro ordenamiento constitucional, por mandato del artículo 10.2 CE, no está limitado solamente por el Convenio Europeo de Derechos Humanos o por la Declaración Universal de Derechos en su literalidad, sino fundamentalmente por la interpretación que de los derechos aquí recogidos haya hecho el Tribunal de Estrasburgo a través de su jurisprudencia.

A este respecto, el Tribunal Europeo de Derechos Humanos ha hecho una interpretación extensiva ${ }^{25}$ del artículo 14 del Convenio Europeo de Derechos Humanos ${ }^{26}$-precepto que recoge el principio de no discriminación- y, aun no previendo expresamente la «orientación sexual» como una de las causas expresas de no discriminación, ha entendido que la protección de esta causa queda cubierta por él, ya que la lista de causas que enumera no tiene carácter taxativo sino meramente indicativo.

En definitiva, el objetivo que se desprende de la lectura de estos textos comunitarios y del Convenio Europeo de Derechos Humanos en la interpretación del Tribunal Europeo de Derechos Humanos ${ }^{27}$ no es sino el objetivo europeo de adoptar la prohibición de discriminación por orientación sexual a su acervo jurídico. Por analogía, y teniendo en cuenta que nuestro ordenamiento debe acomodarse al ordenamiento comunitario, del mismo modo debería interpretarse nuestro artículo $14 \mathrm{CE}$.

${ }^{24}$ Véase L. M. ${ }^{a}$ DíEz PiCAZo, en «Límites...», ob. cit., págs. 18 y ss.

${ }^{25}$ Caso Salgueiro da Silva Monta vs. Portugal, de 21 de diciembre de 1999. En este caso, el Tribunal Europeo de Derechos Humanos consideró que el Tribunal Portugués había vulnerado el artículo 14 del Convenio Europeo de Derechos Humanos, al no haber interpretado como incluida en él la causa de orientación sexual.

${ }^{26}$ Artículo 14 del Convenio Europeo de Derechos Humanos -Prohibición de discriminación-: «El goce de los derechos y libertades reconocidos en el presente Convenio ha de ser asegurado sin distinción alguna, especialmente por razones de sexo, raza, color, lengua, religión, opiniones políticas u otras, origen nacional o social, pertenencia a una minoría nacional, fortuna, nacimiento o cualquier otra situación».

${ }^{27}$ No obstante hay que tener en cuenta que una cosa es el interés comunitario por incluir la prohibición por orientación sexual y algo diferente el llevar hasta sus últimas consecuencias esta consideración. Esto es, a pesar de su interpretación extensiva, son varios los pronunciamientos en los que el Tribunal no ha reconocido plenamente la eficacia de la prohibición de discriminación por orientación sexual, reconociendo a las uniones homosexuales derechos que se les concederían si su opción sexual fuera heterosexual. Bastan para poner algún ejemplo los representativos: STEDH de 22 de octubre de 1981, caso Dugeon, y STEDH de 26 de octubre de 1988, caso Norris. 


\section{La interpretación constitucional de la orientación sexual como causa prohibida de discriminación. Efectos jurídicos}

El objetivo pretendido no es otro que asimilar la orientación sexual a las causas enumeradas en el artículo $14 \mathrm{CE}$, sobre las que recae expresamente la prohibición de discriminación por tratarse de categorías sospechosas. Como se ha explicado, este objetivo bien podría alcanzarse por la vía jurisprudencial, haciendo propios los parámetros aplicados por el Tribunal Supremo Americano, plenamente aplicables al grupo o categoría homosexual. No obstante y teniendo en cuenta la falta de adopción de dichos parámetros por nuestro Tribunal Constitucional para la ampliación de la prohibición de discriminación a nuevas causas mediante su inclusión a través de la cláusula abierta de la «condición o circunstancia personal o social», entendemos que el mandato constitucional de interpretación conforme con los tratados internacionales en materia de derechos fundamentales hace necesario interpretar el artículo $14 \mathrm{CE}$ a la luz de recientes textos europeos -Tratado para la Constitución Europea, aún no en vigor, o Carta Europea de Derechos Fundamentales-, que sitúan la orientación sexual al mismo nivel que el resto de causas históricamente prohibidas, prohibiéndose expresamente la discriminación por orientación sexual. De esta manera se otorgará a la orientación sexual el reconocimiento expreso que debe tener, o al menos, interpretar extensivamente el listado de causas prohibidas, entendiendo que dicha causa está implícita entre ellas y que debe concedérsele el mismo tratamiento jurídico que al resto.

Una vez sentada la inclusión de la orientación sexual dentro del elenco de causas prohibidas del artículo $14 \mathrm{CE}$, tendría la misma posición jurídica que el resto de causas tradicional y expresamente prohibidas por este. En consecuencia, las medidas diferenciadoras en razón a la orientación sexual no superarían su constitucionalidad con un mero examen de mínimos. Tengamos en cuenta que, si se reconoce su equiparación al resto de causas expresamente prohibidas por el artículo $14 \mathrm{CE}$, el legislador deberá superar un juicio muy estricto en sus parámetros para demostrar que la medida diferenciadora no rompe la igualdad y salvar así la constitucionalidad de la norma.

El resultado de la aplicación de un juicio estricto de igualdad a las diferenciaciones normativas a las que se vean sometidas las uniones homosexuales en cualquier ámbito traería como consecuencia el tener que argumentar la razonabilidad de la medida diferenciadora adoptada justificando así su plena constitucionalidad. De no ser así, la medida sería inconstitucional, por discriminatoria.

Así las cosas y trasladando esto al supuesto que nos ocupa, podemos hacer el siguiente planteamiento. En la práctica, y en tanto no se equipare la orientación sexual al resto de causas del artículo $14 \mathrm{CE}$, al legislador no le resulta difícil establecer medidas diferenciadoras con razón en la orientación sexual. Por poner un ejemplo, el legislador podría aprobar una ley de parejas -heterosexuales y homosexuales- en la que se estipule distinto régimen 
y contenido -tal y como ya pasó en algunas comunidades autónomas-, diferenciando a las parejas en razón de su orientación sexual. Obviamente, se trata de una medida diferenciadora, que sin embargo resulta fácilmente superable puesto que tan solo habría que argumentar que no se contrapone directamente con ningún precepto constitucional y que no es abiertamente arbitraria, ya que el legislador siempre podría justificar la diferenciación por alguna razón que salvase su arbitrariedad.

Sin embargo, no resultaría tan fácil la superación de un test más estricto. En tal caso, sobre la orientación sexual -causa diferenciadora de la medida en cuestión- recaería una fuerte sospecha de discriminación que el legislador debería salvar superando el control de finalidad, congruencia y proporcionalidad. Para ello, tendría que argumentarse que la distinción establecida por la norma responde a una finalidad constitucional, además de existir adecuación y proporcionalidad entre la distinción establecida por la norma y su finalidad. Evidentemente, resultaría complicado para el legislador, en este caso como en tantos otros, justificar que la diferenciación entre parejas heterosexuales y homosexuales ante la aplicación de una misma ley de parejas responde a una finalidad prevista constitucionalmente, por lo que menos aún podrían superarse la adecuación de la medida ni su proporcionalidad a la finalidad perseguida.

Quizá podría pensarse que el bien constitucional protegido podría ser la familia, pero en este caso no deberían quedar excluidas las parejas homosexuales, tal y como tendremos ocasión de analizar detenidamente en capítulos posteriores. Tampoco podría argumentarse como finalidad protegida la heterosexualidad, porque la Constitución no protege un tipo específico de desarrollo de la personalidad en su faceta sexual, excluyendo otras; sería tanto como admitir que la Constitución protege a un prototipo de personas por sí misma.

En suma, es interesante tener en cuenta los efectos que podrían generarse si llegara a incluirse definitivamente la orientación sexual dentro del elenco de causas prohibidas, tanto por la discriminación ejercida sobre el colectivo homosexual en general en el ámbito de sus derechos civiles y laborales, como en concreto, en el ámbito de la discriminación ejercida en la esfera de sus derechos personales y familiares como pareja -omitidos, limitados o restringidos históricamente-.

\section{Referencias bibliográficas, normativas y jurisprudenciales}

\section{Referencias bibliográficas}

Boswell, J., Cristianismo, tolerancia social y homosexualidad, Biblioteca Atajos, Barcelona, 1998.

DíAz REVORIO, F. J, Valores superiores e interpretación constitucional, Centro de Estudios Políticos y Constitucionales, Madrid, 1997. 
Díaz Revorio, F. J., La Constitución como orden abierto, Mc Graw Gill, Madrid, 1997.

DíEz PicAzo, L. M., «Límites internacionales al poder constituyente», Revis-

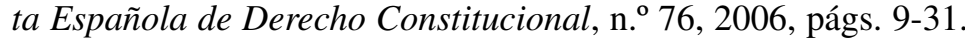

GimÉNEZ Gluck, D., La cláusula de igualdad en la Jurisprudencia del Tribunal Constitucional (Tesis Doctoral).

- Una manifestación polémica del principio de igualdad: acciones positivas moderadas y medidas de discriminación inversa, Tirant Monografías, Madrid, 1998.

Hesse, K., Escritos de Derecho Constitucional (Traducción y selección de Pedro Cruz Villalón), II Edición, Centro de Estudios Constitucionales, Madrid, 1992.

Martín SÁnchez, M., Matrimonio homosexual y Constitución, Tirant lo Blanch, Valencia, 2008.

Rey MARTínez, F., El derecho fundamental a no ser discriminado por razón de sexo, Mc Graw Gill, Madrid, 1995.

RodríGUEZ-PIÑERO, M. y FERNÁNDEZ LÓPEZ, M. F., Igualdad y discriminación, Temas Clave de la Constitución Española, Tecnos, Madrid, 1986.

Referencias normativa europea:

Convenio Europeo de Derechos Humanos, 1950.

Tratado de Ámsterdam.

Resolución del Parlamento Europeo de 1994, elaborada para la Igualdad de homosexuales y lesbianas.

Directiva 2000/78/CE, del Consejo de 27 de noviembre de 2000.

Decisión del Consejo de 27 de noviembre de 2000, por la que se establece un programa de acción comunitario para luchar contra la discriminación (2000-2006).

Referencias jurisprudenciales españolas:

STC 269/1994, de 3 de octubre.

STC 33/1985, de 7 de marzo.

STS, de 15 de noviembre de 1991.

Referencias jurisprudenciales europeas:

STEDH de 22 de octubre de 1981, «asunto Dugeon».

STEDH de 26 de octubre de 1988, «asunto Norris».

STEDH de 21 de diciembre de 1999, «asunto Salgueiro da Silva Monta vs. Portugal» 